\title{
Aprendizagem Baseada em Problemas em um Curso de Medicina: Desafios na sua Implementação
}

\section{Problem-Based Learning in a Medical School: Implementations Challenges}

\author{
Kátia Terezinha Alves Rezende ${ }^{I}(\mathbb{D}$ \\ Maria Cristina Guimarães da Costa ${ }^{I}$ (D) \\ Matheus Eduardo Rodrigues ${ }^{I}$ (D) \\ Silvia Franco da Rocha Tonhom ${ }^{I}$ (B)
}

\section{PALAVRAS-CHAVE}

- Aprendizagem Baseada em Problemas.

- Educação Médica.

- Ensino.

\section{RESUMO}

Introdução: Considerando um currículo integrado e orientado por competência dialógica de acordo com o exposto nas Diretrizes Curriculares Nacionais, a Unidade Educacional Sistematizada (UES) e a Unidade de Prática Profissional (UPP) compõem o currículo de um curso de Medicina de um município do interior paulista. Utilizam-se a Aprendizagem Baseada em Problemas (ABP) na UES e a problematização na UPP como metodologias de ensino, com o objetivo de buscar uma organização que conduza a uma formação coerente com o setor de saúde pública e o cenário de educação nacional. A UES é o foco deste estudo, pois notamos que há divergências entre os docentes sobre o papel do tutor. Com base nisso, a metodologia de ensino vigente na Faculdade de Medicina de Marília (Famema) nos levou aos seguintes questionamentos: "O professor se considera capacitado para atuar no método ABP?" e "De que forma as avaliações contribuem com o processo de ensino-aprendizagem?". Assim, este trabalho teve por objetivo analisar a compreensão do docente acerca de sua capacitação para atuar na ABP e da pertinência das avaliaçães no processo ensino-aprendizagem na UES. Método: Trata-se de estudo do tipo exploratório-descritivo com abordagem de natureza qualitativa. A coleta de dados se deu pela realização de entrevista semiestruturada com professores que desenvolvem atividades na UES do primeiro ao quarto ano do curso de Medicina, selecionaram-se os participantes a partir de uma amostra não probabilística de intenção, totalizando 16 professores, sendo quatro de cada um dos quatro primeiros anos do curso.No exame dos dados, adotou-se a análise de conteúdo na modalidade temática que permitiu a definição de dois eixos temáticos: desafios para a formação docente e potencialidades e limites do processo de avaliação instituído. Resultados: A trajetória da ABP no processo de ensino-aprendizagem sob a ótica dos docentes nos mostrou uma variedade de compreensões. Em relação à formação docente, identificaram-se fragilidades no desenvolvimento do processo tutorial. Além disso, constatou-se que as estratégias utilizadas para a capacitação precisam ser revistas quanto à implementação e à inserção dos profissionais nelas. Observou-se que os docentes demonstram dificuldades em realizar uma avaliação dos estudantes integrando as dimensões afetivas, cognitivas e psicomotoras. Conclusão: Assim, independentemente do tempo de implementação do currículo, a educação permanente deve se constituir como espaço potente para a capacitação docente e a gestão do processo. 


\section{KEYWORDS}

- Problem-Based Learning.

- Medical Education.

- Teaching.

\section{ABSTRACT}

Introduction: Considering an integrated curriculum that is guided by dialogical competence according to the National Curriculum Guidelines, the Systematized Educational Unit (UES) and the Professional Practice Unit (UPP) constitutes the curriculum of a medical course in a municipality in the countryside of the state of São Paulo, Brazil. Problem-Based Learning (PBL) is used in the UES and the problematization is used in the Professional Practice Unit as teaching methodologies, seeking an organization that leads to a training that is coherent with the public health sector and the national education scenario. The UES is the focus of this study because we observed that there are divergences among teachers regarding their role as tutors. Thus, we observed that the teaching methodology currently employed at Famema led us to some questions: Do the teachers consider themselves qualified to work with the PBL method? How do evaluations contribute to the teaching-learning process? Thus, this study aimed to analyze the teachers' understanding of their ability to work with the PBL and the relevance of evaluations for the teaching-learning process in the UES. Method: This is an exploratorydescriptive study with a qualitative approach. Data collection was carried out using a semi-structured interview with teachers who work with the $1^{\text {st }}$ to $4^{\text {th }}$ years in the UES of the medical course, and the selection of the participants was carried out from a non-probabilistic sample of intention, totaling 16 teachers, including four teachers of each of the first four years of the course. The analysis of the data was performed by Content Analysis in the thematic modality, which allowed the definition of two thematic axes: Challenges for teacher training and Potentials and limits of the implemented evaluation process. Results: The trajectory of the PBL in the teaching-learning process from the point of view of teachers showed us a variety of understandings. As for teacher training, weaknesses were identified in the development of the tutoring process, and that the strategies used for training need to be reviewed regarding their implementation and the inclusion of the professionals into the process. Regarding the evaluation, it was observed that the teachers demonstrate difficulties in carrying out an evaluation of the students while integrating the affective, cognitive and psychomotor dimensions. Conclusion: Therefore, regardless the time of the curriculum implementation, Permanent Education should constitute a powerful space for teacher training and process management.

Recebido em 13/8/19

Aceito em 23/7/20

\section{INTRODUÇÃO}

Com base na Lei de Diretrizes e Bases da Educação Nacional - LDB $\left(\right.$ Lei $\mathrm{n}^{\circ}$ 9.394) ${ }^{1}$ e mais tarde nas Diretrizes Curriculares Nacionais do curso de Medicina - $\mathrm{DCN}^{2}$, a Faculdade de Medicina de Marília (Famema) passou por um processo de reestruturação de seu currículo acadêmico que levou a instituição a acompanhar uma tendência discutida mundialmente: aliar ensino com a comunidade, ponto aclamado também pela criação, em 1988, do Sistema Único de Saúde (SUS). Esse processo de mudança e restruturação culminou em 2003 com a participação no Programa de Incentivo às Mudanças Curriculares nos Cursos de Medicina (Promed) ${ }^{3}$, que é estruturado em três eixos, a saber: orientação teórica, abordagem pedagógica e cenários de prática ${ }^{4}$ Assim, o ensino-aprendizagem no curso de Medicina da Famema foi formado pela tríade "aprendizagem centrada no estudante, baseada em problemas e orientada para a comunidade", considerada essencial na estruturação das unidades educacionais multidisciplinares que compõem o currículo da graduação em Medicina. Estabeleceu-se, então, o currículo integrado orientado por competência dialógica, o qual é estruturado em Unidade Educacional Sistematizada (UES) e articulado com a Unidade de Prática Profissional (UPP).

Com isso, no novo modelo curricular da Famema, a abordagem pedagógica desenvolvida na UES teve como base a Aprendizagem Baseada em Problemas (ABP). A ABP surgiu pela primeira vez em 1969, no Canadá, na McMaster University e desde então se propaga pelo mundo como modelo pedagógico na educação de adultos. Trata-se de um processo de ensino-aprendizagem centrado no estudante, isto é, ele é o gerenciador de sua aprendizagem ${ }^{5}$.

Nesse método, os estudantes são organizados em pequenos grupos sob a orientação de um tutor, que necessita dominar os passos tutorias, os princípios que regem o método ativo de ensino-aprendizagem e a técnica que norteia o trabalho em grupo. $O$ processo tutorial deve seguir nove passos $^{6,7}$ : apresentação do problema (leitura pelo grupo); esclarecimento de alguns termos desconhecidos e de dúvidas sobre o problema; definição e resumo do problema, com identificação de pontos relevantes; análise do problema utilizando os conhecimentos prévios, procedimento denominado brainstorm (ou chuva de ideias); desenvolvimento de hipóteses para explicar o problema e identificar lacunas de conhecimento; definição dos objetivos de aprendizagem, em que os estudantes elaboram questões a serem pesquisadas e respondidas; busca ativa de informação e estudo individual; compartilhamento das informações obtidas e aplicação na compreensão do problema proposto; e, por último, avaliação do trabalho do grupo e dos seus membros.

Na UES, o desempenho do estudante é verificado por meio de um instrumento de avaliação que contribui com o processo ensinoaprendizagem preenchido pelo professor que o acompanhou. Compondo as avaliações, temos ainda o Exercício de Avaliação Cognitiva (EAC), que é um instrumento de resposta escrita que contempla os conteúdos estudados, de caráter multidisciplinar, abordando aspectos biológicos, psicológicos e sociais e mantendo a integração básico-clínica ${ }^{8}$.

REVISTA BRASILEIRA DE EDUCAÇÃO MÉDICA

2 44 (4) : e119; 2020 
Considerando o currículo do curso de Medicina da Famema e com base em percepções identificadas de forma empírica, nota-se que há divergências entre os docentes quanto ao seu papel como tutor. Alguns professores não desenvolvem o processo ensino-aprendizagem de acordo com o que é preconizado, ou seja, alguns passos tutoriais deixam de ser seguidos, como a elaboração de hipóteses e a avaliação do desempenho do grupo e do estudante.

Ante esse cenário, apontam-se os seguintes questionamentos:

- O professor se considera capacitado para atuar no método ABP?

- De que forma as avaliações contribuem com o processo de ensino-aprendizagem?

Assim, o objetivo desta pesquisa foi analisar a compreensão do docente acerca da sua capacitação para atuar na $\mathrm{ABP}$ e o desenvolvimento das avaliações no processo ensino-aprendizagem na UES.

\section{METODOLOGIA}

Trata-se de uma pesquisa de campo, do tipo exploratório-descritivo, a partir de uma abordagem qualitativa. Essa escolha se deu pelo fato de resguardar domínio em descrever um determinado fenômeno para ampliar o conhecimento, assim como caracterizá-1o ${ }^{9}$. O estudo de campo tem sua importância à medida que o pesquisador necessita ir ao espaço em que o fenômeno ocorre e busca reunir um conjunto de informações a serem coletadas e documentadas. A análise qualitativa, por sua vez, pode explorar sentidos e significados, como valores, crenças, hábitos, atitudes e opiniões fornecidas $^{10}$.

O estudo foi realizado na Famema, localizada em um município do interior, na região do centro-oeste do estado de São Paulo. É uma instituição de ensino pública, fundada em 1966, que oferece os cursos de Medicina e Enfermagem com um ingresso de 80 e 40 estudantes por ano, respectivamente. $\mathrm{O}$ curso de Medicina é de período integral, de modalidade de ensino presencial e tem o prazo mínimo para sua conclusão de seis anos. Possui como nível acadêmico a graduação e como grau acadêmico o bacharelado ${ }^{11}$.

A população deste estudo foi formada por docentes que desenvolvem suas atividades na UES do primeiro ao quarto ano do curso de Medicina, que totalizam 65 docentes tutores. Destes, $14(21,5 \%)$ professores atuam no primeiro ano, $16(24,6 \%)$ no segundo, $17(26,2 \%)$ no terceiro e 18 $(27,7 \%)$ no quarto. Nos três primeiros anos, os docentes são de diversas formações profissionais (médicos, enfermeiros, biólogos, farmacêuticos, entre outros), e o quarto ano é composto exclusivamente por tutores médicos. A seleção dos participantes foi realizada a partir de uma amostra não probabilística de intenção, sendo quatro professores de cada um dos quatro primeiros anos do curso de Medicina, totalizando 16. Foram escolhidos também a partir das variáveis sexo, tempo em que desenvolve a $\mathrm{ABP}$ e formação profissional, garantindo assim uma amostra que permitiu abranger múltiplas dimensões e investigar o problema em sua totalidade.

Realizou-se a coleta de dados por meio de entrevista semiestruturada que foi gravada e transcrita por um dos pesquisadores. Por meio desse método de coleta de dados, é possível ampliar o detalhamento das informações adquiridas e examinar minuciosamente a subjetividade das respostas dos docentes ${ }^{12}$.

O estudo foi aprovado pelo Comitê de Ética em Pesquisa Envolvendo Seres Humanos da Famema no 1.273.569 - Certificado de Apresentação para Apreciação Ética (CAAE) no 49104915.0.0000.5413. Os professores que concordaram em participar da pesquisa assinaram o Termo de Consentimento Livre e Esclarecido (TCLE) antes da coleta de dados.

A análise foi realizada a partir da análise de conteúdo na modalidade temática, que tem como propósito descobrir os núcleos de sentidos da comunicação que representem algo para o alcance dos objetivos ${ }^{10,13}$. Inicialmente, fez-se a leitura exaustiva do material para que houvesse a impregnação do conteúdo. Dessa forma, foi possível ter uma visão do conjunto, apreender as particularidades, elaborar pressupostos, escolher a forma de classificação inicial e, por fim, definir os conceitos teóricos que orientaram a análise.

Em seguida, realizou-se a exploração do material, distribuindo-se os trechos das entrevistas em uma classificação que contemplou a formação docente e o desenvolvimento da avaliação da tutoria.

A partir de então, fez-se uma leitura do conteúdo de cada classe, de modo a estabelecer um diálogo entre as partes do texto de análise. A seguir, identificaram-se, por meio de inferência, os núcleos de sentido que reorganizados constituíram dois eixos temáticos: desafios para a formação docente e potencialidades e limites do processo de avaliação instituído, conforme mostra o Quadro 1.

\section{RESULTADOS E DISCUSSÃO}

Caracterização dos participantes

Participaram da pesquisa três $(18,75 \%)$ biólogos, um (6,25\%) biomédico, três $(18,75 \%)$ farmacêuticos, um $(6,25 \%)$ enfermeiro e oito (50\%) médicos, totalizando uma população com oito profissionais (50\%) do sexo masculino e oito (50\%) do sexo feminino.

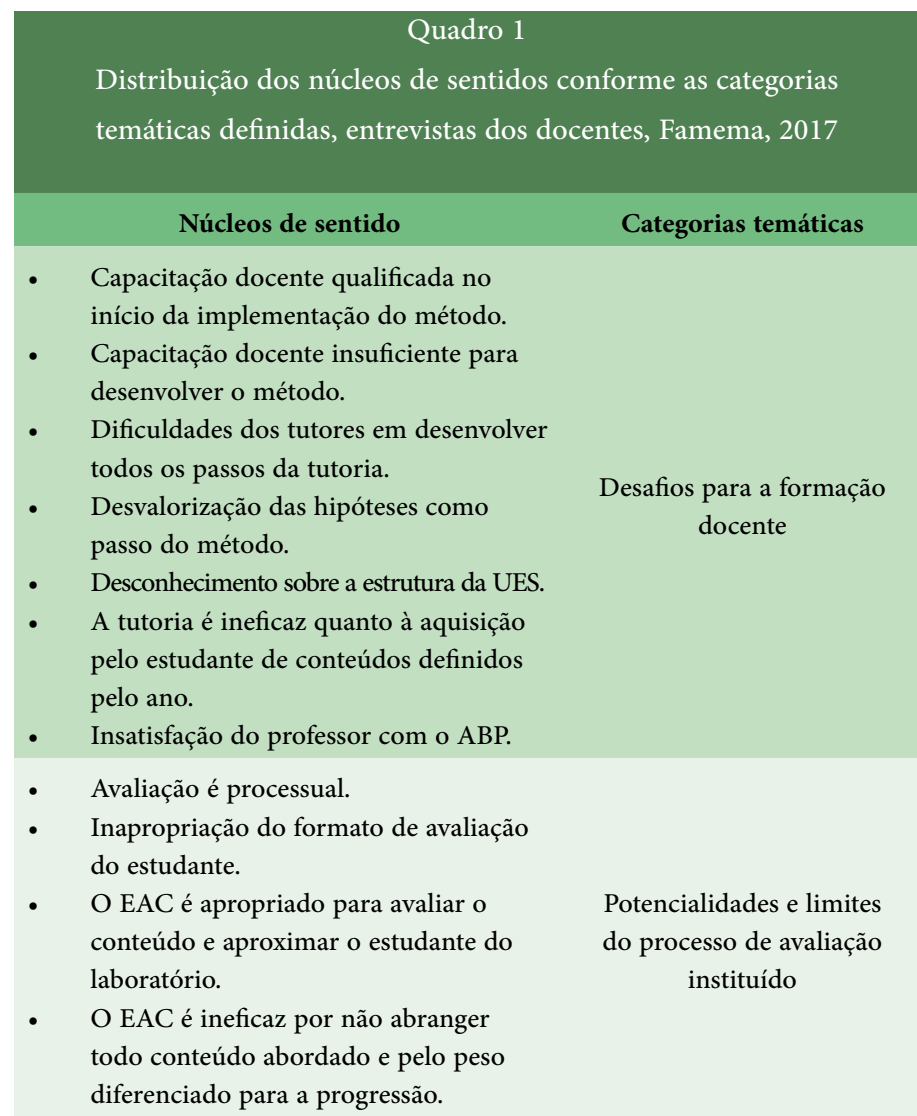

Fonte: elaborado pelos autores.

REVISTA BRASILEIRA DE EDUCAÇ̃̃o MÉDICA

3 44(4) : e119; 2020 
Em relação à idade, dois (12,50\%) professores tinham mais de 60 anos; seis $(37,50 \%)$, entre 50 e 59; cinco $(31,25 \%)$, entre 40 e 49 ; e três $(18,75 \%)$, entre 30 e 39 anos.

Quanto ao tempo de contratação, dois (12,50\%) tutores tinham entre zero e cinco anos; dois (12,50\%), entre seis e dez; dois (12,50\%), entre 11 e 15 ; dois (12,50\%), entre 16 e 20; e oito (50\%), mais de 20 .

Dos entrevistados, oito (50\%) professores participaram de capacitações realizadas no início do processo de implantação do método ABP na Famema e oito (50\%) tiveram sua inserção no método após o ciclo inicial de capacitação.

Temas

\section{Desafios para a formação docente}

Neste estudo, parte dos entrevistados foi submetida à educação continuada (EC) realizada por especialistas externos à instituição, entre os anos de 1996 e 1997, quando se teve início o processo de mudança curricular.

Na época tinha muitos cursos de educação continuada e a gente fazia esses cursos de educação continuada sobre avaliação, dinâmica de grupo, e vinham pessoas também de fora da instituição que, não necessariamente, tinham experiência com o PBL, mas nessas frentes de trabalho, avaliação, dinâmica de grupo e etc. No começo foi um investimento muito maciço e depois a instituição ganhou autonomia (E4).

Em sua maioria, os professores que participaram desse processo de capacitação inicial o consideraram extremamente produtivo porque obtiveram um embasamento necessário para a realização e adequação com a nova proposta pedagógica: "Eu acho que o que aconteceu lá no início era algo muito dinâmico, era algo muito prático; a gente estava vivenciando aquela prática e era constante. Eu acho que contribuiu bastante para que eu entendesse esse processo" (E7).

O estabelecimento de inovações pedagógicas vem acompanhado de um sentimento de incerteza, pelo medo do desconhecido, principalmente por aqueles que não se sentem parte da implantação do modelo. Portanto, diversos autores afirmam ser de essencial importância a implantação de um programa de desenvolvimento docente para melhorar o seu desempenho na universidade, evitando a frustração e o abandono da atividade acadêmica ${ }^{14}$.

A capacitação docente na Famema passou por um período caracterizado pelo forte investimento institucional na formação de professores, momento em que se implantou o método ABP. Com esse processo de mudança pedagógica, foi necessária uma intensa atuação com o docente que trabalharia nessa nova abordagem. Por conta disso, desenvolveram-se programas de capacitação de tutores antes do início da realização das atividades ${ }^{11}$.

Desenvolveu-se também a EC, durante o processo, que abordava temas como bioética, princípios da educação de adultos, medicina baseada em evidências, dinâmica de grupo, entre outros ${ }^{15}$.

Com o passar dos anos, esses docentes foram responsáveis pela formação de novos tutores, que, ao participarem de todo o processo, qualificaram-se e assumiram primeiro o papel de cotutores e posteriormente de tutores. Entretanto, somente essa forma de capacitação não foi considerada suficiente pelos entrevistados:
Na verdade, não teve capacitação. E eu fui como cotutora e assim como o outro tutor fazia, é o jeito que eu faço hoje. [...] da própria faculdade teve uma ou outra capacitação, não necessariamente, para a tutoria especificamente, do processo tutorial (E1).

Tradicionalmente, quando se analisa o corpo docente das universidades, é nítida a forte formação técnico-científica em contraponto às deficiências na formação didático-pedagógica. Assim, surge a necessidade de estratégias que permitam uma superação dessa defasagem, como a implantação da educação permanente (EP). A capacitação para atuação docente também pode acontecer de diversas formas, com destaque, além das capacitações promovidas pelas universidades ou pela pós-graduação, para a própria troca com os estudantes, a troca entre os pares, a produção científica ou para grupo de estudos ${ }^{16}$.

A EP é uma abordagem pedagógica desenvolvida no setor da saúde que permite efetuar relações entre docência e atenção à saúde ${ }^{17}$. Assim, por meio do trabalho, há a possibilidade de reorientação das práticas dos profissionais, superando as lacunas do campo da formação ${ }^{18}$.

Desde 2002, a Famema passou a realizar a EP como elemento central em seu Programa de Desenvolvimento Docente (PDD) que tem como objetivo, partir da reflexão que foca o cotidiano dos docentes, promover o crescimento do grupo e dos seus componentes com a construção de aprendizagem e transformações da prática. As atividades são frequentemente realizadas em grupos de, no máximo, 12 docentes, com encontros semanais de 60 minutos. O trabalho é coordenado por dois docentes em cada grupo, com o objetivo de trabalhar o processo pedagógico e grupal ${ }^{11}$.

Atualmente, a maioria dos entrevistados refere pouca adesão ao processo de EC e não considera que as atividades desenvolvidas na EP sejam suficientes para dar densidade teórica ao processo ensino-aprendizagem.

Hoje eu não faço mais nenhuma [EC], cansei, literalmente. Porque as capacitações não mudaram, e aí a gente vai tendo tanta coisa para fazer que eu não faço mais (E10).

[...] na EP a gente discute muito o problema com estudante, uma ou outra dificuldade, mas assim a parte teórica que poderia ser trabalhada na EP acaba não sendo, por conta de ser também um espaço para discutir esses outros tipos de problema (E1).

Treviso e $\operatorname{Costa}^{16}$ encontraram alguns fatores que influenciam na baixa adesão docente às atividades de capacitação propostas pelas instituições de ensino, com a falta de tempo, o impedimento de participar por motivos pessoais e uma abordagem pouco atraente. Os autores propõem que sejam realizadas estratégias criativas nas capacitações das instituições de ensino superior a fim de estimular a motivação dos docentes, promover um espaço de troca de conhecimentos e não afugentar quem participa. Além disso, destacam a importância de um planejamento e uma divulgação com antecedência, de modo a garantir uma melhor adesão de todos os participantes.

Nesse sentido, observa-se uma oportunidade de rever a maneira como a Famema realiza tanto sua EP quanto as ações de EC. Mesmo os docentes com menos tempo de atuação na instituição se deparam, nos encontros, com pautas de assuntos repetidos e/ou pouco atraentes. Assim, questiona-se se o espaço da EP está sendo utilizado somente para a exposição de dificuldades encontradas nas sessões de tutoria ou demais

\footnotetext{
$4 \mid$\begin{tabular}{l|l} 
REVISTA BRASILEIRA DE EDUCAÇÃO MÉDICA \\
\hline 44 (4) : e119; 2020
\end{tabular}
} 
problemas institucionais, não se constituindo um espaço para subsidiar a construção teórica a respeito do processo de ensino-aprendizagem. Além disso, é imprescindível verificar quais demandas consideradas importantes devem ser solucionadas para a fluidez do processo, pois a EP não está sendo, ainda, uma ferramenta de gestão.

Percebe-se um sentimento de frustração nos docentes da Famema entrevistados. Muitos apontam a baixa adesão ou insatisfação com o processo de EP. Além disso, os docentes inseridos após a implantação do método não relatam o mesmo entusiasmo vislumbrado por aqueles que estavam presentes desde o início. Sentem a falta de uma capacitação para sua atuação e desqualificam a realizada apenas no modelo de cotutoria.

Tais sentimentos acabam por se refletir na ação do docente como tutor. Um dos aspectos encontra-se no fato que nenhum dos tutores entrevistados cita os nove passos do processo tutorial. Nesse sentido, somente a minoria dos tutores mencionam a elaboração de hipóteses e a avaliação no desenvolvimento do processo.

[...] tento desenvolver nos passos que a gente faz aqui, obviamente não consigo seguir 100\%, tem muita coisa também que eu não vou ser hipócrita de falar que eu concordo $100 \%$ com o método. Tento! Não vou eu corrigir o método, quem sou eu pra corrigir o método, mas dentro do grupo, ali se o grupo permite, se está à vontade, a gente vai discutindo os assuntos e tentar digerir o mais profundamente possível em todo e qualquer assunto (E13).

Faço leitura individual, depois leitura coletiva, esclarecimento dos termos. Brainstorm é um processo que eu valorizo muito. Quando eu faço processo tutorial, gosto de explorar bastante conhecimentos prévios para a gente conseguir avançar. Avaliação individual e coletiva, e depois, dando continuidade às discussões, eu costumo participar, estar bem atento às discussões (E4).

Os noves passos do processo tutorial se baseiam no processo científico, e o não seguimento deles acaba por comprometer a aprendizagem significativa, uma vez que esta de fato se concretiza a partir do momento em que o estudante se encontra em uma situação de conflito cognitivo, fator afetivo fundamental na busca, garantindo mudanças em sua estrutura de pensamento ${ }^{19}$.

Destaca-se ainda a importância do seguimento dos passos tutoriais, que garantem bases educacionais para desenvolver habilidades essenciais na prática profissional dos futuros médicos, como a construção de raciocínio hipotético-dedutivo e a obtenção da habilidade de autogerenciamento do seu conhecimento ${ }^{20}$.

Além disso, identifica-se que os docentes desconhecem as demais atividades da UES ou ainda citam a UPP como pertencente àquela. Poucos tutores citam a consultoria, a conferência e as atividades práticas. Aqui, ainda se consegue observar a ideia presente em muitos docentes de que a UES é composta apenas ou exclusivamente pela tutoria, desvalorizando os demais cenários de ensino-aprendizagem.

Não sei nem te descrever todas. Sei que vocês têm Unidade de Prática Profissional, mas eu não sei descrever todas (E2).

Eu não sei todas. Sei que tem as palestras... e depois eu não sei mais (E15).
Os docentes apontam que a unidade contribui para hiatos na formação em relação ao conteúdo conferido ao estudante.

[...] se a gente olhar para os pressupostos teórico-pedagógicos, olhando a nossa construção curricular e que o nosso currículo é orientado por competências, nós precisaríamos trazer na unidade educacional sistematizada subsídio cognitivo para permitir que o estudante de Medicina desenvolvesse a sua prática médica a partir da sua formação. [...] Só que a gente ainda não tem tanta clareza disso. Talvez por não ter tanta essa clareza, no meu ponto de vista, nós permitimos que alguns hiatos de formação cognitiva do estudante aconteçam aqui na Famema (E12).

Na ABP, o tutor não define especificamente o conteúdo que é desenvolvido como no modelo tradicional de ensino. Por ser uma metodologia centrada no estudante, os professores que não são devidamente capacitados para o método se sentem desconfortáveis por não haver a transmissão de conhecimento. Esse novo papel é observado com uma das principais barreiras para adotar metodologias ativas em escolas previamente estabelecidas no modelo tradicional de ensino. Identifica-se relutância dos professores em institucionalizar tal inovação quando há falta de experiência e fundamentos teóricos ${ }^{21}$.

A participação nos espaços de EP pode possibilitar a reflexão sobre as práticas docentes, já que se trata de um recurso fundamental para os professores que fizeram parte da implantação do método ABP na Famema e representa uma oportunidade de capacitação para aqueles inseridos após esse processo. Destaca-se ainda a possibilidade de se repensar como está sendo realizada a capacitação de professores e sua inserção na ABP, uma inovação pedagógica que carece de importantes movimentos de inclusão e embasamento teórico para que eles promovam a aprendizagem significativa.

\section{Potencialidades e limites do processo de avaliação instituído}

Uma vez que na $A B P$ o estudante é o principal sujeito de sua aprendizagem, espera-se que a avaliação seja um instrumento norteador de transformação no processo de ensino-aprendizagem dele. Assim, antes de punir ou vigiar, a avaliação, seja ela somativa ou formativa, oral ou escrita, diária ou semestral, tem o papel de subsidiar a autoavaliação e conferir para o estudante a habilidade de identificar suas qualidades e fragilidades com tempo hábil para sua recuperação ${ }^{6,8}$.

Identifica-se que muitos professores consideram a avaliação diária realizada na tutoria o melhor momento para acompanhar o estudante e levá-lo a refletir sobre suas fragilidades e potencialidades.

Então cada dia eu avalio aquele aluno, principalmente para que ele não seja surpreendido com um suficiente ou um insuficiente lá no final (E5).

Os formatos de avaliação eu acho que são muito amplos e que muitas vezes, na hora que você lê, não diz muito, fica muito vago. Acho que está na hora de rever os formatos (E8).

Como os alunos fazem uso desse formato, eu acho que ainda é bastante inadequado, por falta de conhecimento, por preguiça dos dois lados, porque avaliar é difícil, você precisa de um tempo para sentar, pensar no seu aluno, e escrever aqueles formatos [...] (E10).

$5 \mid$\begin{tabular}{l|l} 
REVISTA BRASILEIRA DE EDUCAÇÃO MÉDICA \\
\hline 44 (4) : e119; 2020
\end{tabular} 
Trata-se da avaliação formativa que tem como finalidade indicar para a instituição, para o professor e para o estudante os resultados obtidos durante o curso, sendo um processo contínuo e evolutivo que, integrando as dimensões afetivas, cognitivas e psicomotoras, tem a função de promover o desenvolvimento não só do estudante, como também da faculdade e dos profissionais envolvidos no processo ${ }^{8}$.

Além disso, a aproximação do professor com o estudante, os atores nesse processo avaliativo, confere maior segurança e acompanhamento do discente.

Apesar das potencialidades apontadas na avaliação realizada em tutoria, o formato avaliativo de desempenho do estudante na UES é alvo de críticas por parte dos professores.

O formato deve ser uma síntese de avaliações realizadas pelos professores durante o desenvolvimento das tutorias ${ }^{22}$. Porém, verifica-se que os professores o consideram de difícil preenchimento, trabalhoso e que não reflete em sua totalidade o que é explorado durante o processo tutorial.

Os professores citaram o EAC como a principal forma de avaliação cognitiva. Esse exercício foi considerado uma ferramenta avaliativa adequada por reaproximar o estudante dos assuntos abordados e por levá-lo aos laboratórios. Esse instrumento também favorece a discussão de um caso-problema e permite o desenvolvimento de um raciocínio científico: "o diferencial do EAC reside na existência de uma situaçãoproblema, uma vinheta maior, eu vejo nela o diferencial. Porque, se você muda o processo de ensino-aprendizagem, a avaliação também tem que ser modificada" (E4).

Apesar das potencialidades apontadas em relação ao EAC, evidenciase o entendimento da avaliação com sua característica de vigiar e punir o estudante: "Eu particularmente tenho muito medo do EAC porque você transforma toda uma metodologia em um regresso, como se fosse o dia de vestibular" (E6).

Nesse sentido, observa-se que a prática da avaliação cognitiva ainda determina ou direciona o conteúdo a ser estudado, diferentemente do que se pretende com os recentes investimentos nas novas estratégias pedagógicas em que se espera que a avaliação seja consequência de um processo de aprendizado estimulante e de fato significativo $^{22}$.

Esse exercício também é criticado por não conseguir abranger todo conteúdo.

Sabemos que isso [EAC] é insuficiente, não dá pra abordar todo o conteúdo em questões dissertativas, senão a gente vai ter uma prova com 20, 25 questões, que eu acho que para o estudante isso seria bastante complicado (E12).

Eu acho que EAC é bom, tem que ter pra ver se ele está realmente fixando aquilo que ele está estudando (E15).

Os professores identificam que o EAC tem um peso diferenciado na progressão do estudante, pois eles valorizam esse exercício em detrimento da avaliação de desempenho no processo tutorial.

[...] o que reprova na escola? O EAC. Por que tutoria não reprova? Porque no meu ponto de vista é mal avaliado. Não se dá o valor adequado para o formato de avaliação de desempenho na tutoria que deveria ter porque, na teoria, no caderno de avaliação, o desempenho do estudante ele tem que ser $100 \%$ satisfatório. Tanto no EAC quanto no processo tutorial. E qual estudante tem $100 \%$ de desempenho na tutoria? E na hora que a gente lê os formatos, a gente não vê isso. Porque o professor talvez não tenha essa formação, não tenha essa capacitação (E12).

Quanto à avaliação, observam-se, na compreensão dos professores, diversas contradições. Uma delas, por exemplo, é a valorização da avaliação diária, porém eles apontam também fragilidades no preenchimento do formato avaliativo. Ainda, os docentes demonstram dificuldades em realizar uma avaliação dos estudantes integrando as dimensões afetivas, cognitivas e psicomotoras.

Nesse sentido, questiona-se a necessidade de capacitação docente para realizar a avaliação de desempenho, considerando os critérios definidos no formato, ou se este precisa ser revisto de forma a explicitar o que se espera do estudante.

Outra contradição é a valorização de aspectos avaliativos característicos do ensino tradicional como o foco no conteúdo e com caráter punitivo, além de a avaliação cognitiva ser um instrumento norteador do estudo; princípios que se contrapõem à aprendizagem significativa.

\section{CONCLUSÕES}

Considerando os objetivos desta pesquisa, foi possível avaliar o processo ensino-aprendizagem por meio da ABP na UES, na perspectiva do docente do curso de Medicina da instituição pesquisada.

Sob a ótica dos docentes, a trajetória da ABP no processo de ensinoaprendizagem da Famema nos mostra uma variedade de compreensões baseadas nas diversas experiências vividas pelos entrevistados, nas diferentes atuações profissionais, no tempo em atividade no método, na série em que atua e, até mesmo, nas percepções e nos valores pessoais. Essas compreensões nos permitiram traçar um panorama desde a implantação do método até os dias atuais.

Em relação à formação docente, destaca-se que a participação nos espaços de EC e EP é fundamental para os professores. Entretanto, as estratégias utilizadas necessitam ser revistas quanto à implementação e à inserção dos profissionais.

Quanto à avaliação, observamos que os docentes demonstram dificuldades em realizar uma avaliação dos estudantes integrando as dimensões afetivas, cognitivas e psicomotoras.

Assim, independentemente do tempo de implementação do currículo, a EP deve se constituir como espaço potente para capacitação docente e gestão do processo. Nesse sentido, a instituição necessita repensar a forma como está sendo realizada essa formação, buscando a compreensão do método de ensino-aprendizagem e adesão a ele.

As reflexões oportunizadas pelo estudo, embora seja de um contexto local, permitem extrapolar para outras instituições de ensino, as quais estão buscando inovações educacionais que visem à aprendizagem significativa e ao currículo integrado.

\section{AGRADECIMENTOS}

À Fundação de Amparo à Pesquisa do Estado de São Paulo (Fapesp), Processo n 2015/25784-0. 


\section{REFERÊNCIAS}

1. Brasil. Lei no 9394/96, de 20 de dezembro de 1996. Estabelece as diretrizes e bases da educação nacional. Diário Oficial da União, Brasília; 1996; Seção1, p. 278-341.

2. Brasil. Diretrizes Curriculares Nacionais do Curso de Medicina. Conselho Nacional de Educação. Câmara de Educação Superior. Resolução nº 3, de 20 de junho de 2014.

3. Faculdade de Medicina de Marília. Programa de Incentivo às Mudanças Curriculares dos Cursos de Medicina (Promed): uma nova escola médica para um novo sistema de saúde. Projeto final da Famema. Marília: Faculdade de Medicina de Marília; 2003.

4. Faculdade de Medicina de Marília. Relatório da pesquisa de avaliação do resultado do processo de formação de médicos da Famema. Marília: Faculdade de Medicina de Marília; 2008.

5. Neville AJ, Norman GR. PBL in the undergraduate MD program at McMaster University: three iterations in three decades. Acad Med. 2007;82(4):370-4.

6. Komatsu RS. Aprendizagem Baseada em Problemas na Faculdade de Medicina de NN: sensibilizando o olhar para o idoso [tese]. Marília: Universidade Estadual Paulista "Júlio de Mesquita Filho"; 2003.

7. Kamp RJA, Dolmans DHJM, Van Berkel HJM, Schmidt HG. The effect of midterm peer feedback on student functioning in problem-based tutorials. Adv Health Sci Educ. 2012;18(2):199-213. doi: 10.1007/ s10459-012-9364-1.

8. Faculdade de Medicina de Marília. Caderno de avaliação do estudante: cursos de Medicina e Enfermagem. Marília: Faculdade de Medicina de Marília; 2011.

9. Marconi MA, Lakatos EM. Fundamentos de metodologia científica. 7a ed. São Paulo: Atlas; 2010.

10. Minayo MCS, organizadora. Pesquisa social: teoria, método e criatividade. Petrópolis: Vozes; 2016.

11. Faculdade de Medicina de Marília. Caderno do Programa de Desenvolvimento Docente. Marília: Faculdade de Medicina de Marília; 2008.

12. Sampieri RH, Collado CF, Lucio PB. Metodologia de pesquisa. 3a ed. São Paulo: McGraw-Hill; 2012.

13. Bardin L. Análise de conteúdo. São Paulo: Edições 70; 2011.

14. Venturelli J, Fiorini VML. Programas educacionais inovadores em escolas médicas: capacitação docente. Rev Bras Educ Med. 2001;25:7-21.

15. Feuerwerker L. Além do discurso de mudança na educação médica: processos e resultados. São Paulo: Hucitec; 2002.
16. Treviso P, Costa BEP. Percepção de profissionais da área da saúde sobre a formação em sua atividade docente. Texto \& Contexto Enferm. 2017;26(1):e5020015 [acesso em 15 de mar 2019]. Disponível em: http://www.index-f.com/textocontexto/2017/26116p.php.

17. Brasil. Portaria $n^{\circ} 198 / G M / M S$, de 13 de fevereiro de 2004. Institui a Política Nacional de Educação Permanente em Saúde como estratégia do Sistema Único de Saúde para a formação e o desenvolvimento de trabalhadores para o setor e dá outras providências. Diário Oficial da União; 2004.

18. Santos AR, Coutinho ML. Educação permanente em saúde: construções de enfermeiros da estratégia saúde da família. Rev Baiana Saúde Pública. 2014;38:708-24. doi: 10.5327/Z0100-02332014380300016.

19. Tsuji H., Aguilar-Silva RH. Aprender e ensinar na escola vestida de branco: do modelo biomédico ao humanístico. São Paulo: Forte; 2010.

20. Moro C, McLean M. Supporting students' transition to university and problem-based learning. Medical Science Educator. 2017;27:353-61. [acesso em 5 maio 2020] doi: 10.1007/s40670-017-0384-6.

21. Borges MC, Chachá SGF, Quintana SM, Freitas LCC, Rodrigues MLV. Aprendizado baseado em problemas. Medicina (Ribeirão Preto). 2014;47:301-7 [acesso em 5 ago 2020]. Disponível em: http://revista. fmrp.usp.br/2014/vol47n3/8_Aprendizado-baseado-em-problemas.pdf.

22. Moraes MAA, Tonhom SFR, Hafner MLMB, Gomes R, organizadores. Avaliação nos cursos de medicina e enfermagem: perspectivas e desafios. Curitiba: CRV; 2012.

\section{CONTRIBUIÇÃO DOS AUTORES}

Todos os autores participaram da concepção e do planejamento do projeto de pesquisa, da coleta de dados, da análise e interpretação dos dados e da redação e revisão final.

\section{CONFLITO DE INTERESSES}

Declaramos não haver conflito de interesses

\section{ENDEREÇO PARA CORRESPONDÊNCIA}

Sílvia Franco da Rocha Tonhom. Avenida Santa Helena, 909, casa

131, Jardim Alvorada, Marília, SP, Brasil. CEP: 17513-322.

E-mail: siltonhom@gmail.com 